\title{
Recognizing and addressing implicit gender bias in medicine
}

\author{
Katrina Hui MD MS, Javeed Sukhera MD PhD, Simone Vigod MD MSc, Valerie H. Taylor MD PhD, \\ Juveria Zaheer MD MSc
}

- Cite as: CMAJ 2020 October 19;192:E1269-70. doi: 10.1503/cmaj.200286

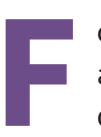

or more than a decade, women have predominated among Canadian medical school graduates, according to data from the Canadian Post-M.D. Education Registry (CAPER). Although, as a profession, medicine still sees pervasive discrimination that disadvantages certain groups over others, one might argue that gender equity is an area in which progress has been made. Institutions have issued statements on the importance of gender equity, and impressive organizational programs have provided networking, mentorship and leadership training to support women's careers. ${ }^{1}$ However, women remain underrepresented in senior faculty and leadership roles in academic medicine, comprising only $22 \%$ of professors, $36 \%$ of associate professors and $24 \%$ of medical school deans in Canada as of 2016/17. ${ }^{2}$ Women physicians still have fewer opportunities for promotion, fewer opportunities to publish, lower pay and less funding for research. ${ }^{3}$ Lack of gender parity in professions can be understood as a product of biases occurring at both an individual and an organizational or systemic level, through policies and procedures that amplify and further perpetuate discrimination. Biases may be explicit or implicit. We discuss implicit gender bias in the medical profession and how it could be addressed.

When biases that drive actions, policies and procedures are explicit, the attitudes underpinning them are clear, even if individuals choose to conceal them. For example, a decision to hire a man over a woman because of a stated perception of increased dedication to his career is clearly identifiable and can be challenged; this explicit bias may be amenable to correction by instituting processes that require that such perceptions be discounted. Implicit biases, however, are hidden from conscious awareness; they are attitudes that individuals do not realize are affecting their understanding and actions and, because they are more difficult to recognize, they are harder to address.

Implicit gender bias is pervasive across the continuum of medical training and practice, and research offers insight into how it may be driving the persistence of the gender gap in medicine. A qualitative study showed that women residents were less likely to be attributed traits that are perceived as traditionally masculine, such as "assertiveness" and "autonomy," and an analysis of language used

\section{KEY POINTS}

- Although Canada has seen gender equity among medical graduates for more than a decade, women are still underrepresented in senior faculty and leadership roles in the profession and face more challenges in research careers.

- Implicit gender bias is one part of a broader set of mechanisms that drive gender inequities in medicine, but it is difficult to tackle because it is usually not consciously appreciated.

- Implicit gender bias has been shown to persist from early in medical training and to play a role in gender disparities in hiring, advancement and pay as physicians' careers progress.

- The most promising educational interventions targeting implicit bias use a multipronged approach aimed at tackling awareness of implicit gender bias and structural measures to minimize its effects.

in medical student evaluations showed that women are less likely to be seen as career oriented than men, despite comparable overall evaluation scores. ${ }^{5}$ Moreover, women tend to be described as "compassionate," "sensitive" and "enthusiastic," compared with terms often used to describe men, such as "a quick learner." This trend persists through training and may affect career decisions, as shown in a recent, large observational study of data on surgeons. ${ }^{6}$ In the research domain, women investigators receive less funding than men; 1 recent study that explored gender difference in Canadian Institutes of Health Research awards found that less favourable assessments of women as principal investigators drove lower award rates, rather than the quality of their proposals. ${ }^{7}$ This aligns with decades-old Swedish data that suggest women needed 2.5 times as many impactful publications to receive an equivalent score on grant reviews as their male counterparts, ${ }^{8}$ and a 2016 study of National Institutes of Health data that showed different evaluation standards were applied to men and women in grant funding. ${ }^{9}$ Such biases may contribute to barriers women face in medical career advancement, including reduced opportunities, which may affect pay, hiring and promotion. Gender bias may also become internalized, leading women to perceive their own strengths as insufficient or to avoid "outperforming" men, ${ }^{10}$ 
influencing their decisions to pursue certain careers or to attain leadership positions.

Although implicit biases are, by definition, outside of our awareness, evidence-informed approaches can be used to minimize them. Before implicit biases can be managed on an individual level, they must be brought into conscious awareness. An academic health centre found that a brief intervention involving an implicit gender bias self-assessment and educational presentation changed faculty members' awareness of gender bias; departments that received the intervention subsequently increased hiring of women at twice the rate of those in departments that did not receive the intervention. ${ }^{11}$ Even though this outcome was not directly attributable to the training, it appeared to help by increasing awareness. Similarly, one university offered a workshop consisting of implicit gender bias education, practical tools and small group facilitation to 98 science, technology, engineering, mathematics and medicine departments, resulting in faculty feeling better equipped to promote gender equity. Two years later, departments that underwent training hired higher proportions of women as new faculty, compared with control groups. ${ }^{12}$

Bias training alone may be insufficient to produce meaningful and sustained change, however, and may be more effective if it is delivered as part of, and to inform the design of, more comprehensive initiatives to change structural bias. Such initiatives include measures such as policy changes and leadership support. ${ }^{13}$ Specifically, pro-equity efforts must include evaluation to ensure they are not unwittingly exacerbating biases by triggering dissonance (which can strengthen biases), ${ }^{13}$ promoting an illusion of fairness, using evaluation standards that are prone to subjectivity, and neglecting social penalties when prescriptive gender norms are violated. ${ }^{14}$ Structural initiatives that may address the consequences of implicit gender bias in the medical profession include application blinding; increased diversity on selection and planning committees; critical examination of biased language in teaching, evaluation, nomination and selection processes; and support with flexible child care. ${ }^{14}$

Implicit gender bias represents only one part of a broader set of mechanisms that drive gender inequities in medicine, but it is difficult to tackle because it is likely under-recognized. Improving understanding of implicit gender bias may inform comprehensive, multilevel strategies to counter it. Further exploration of experiences at the intersection of gender, race, sexuality and other identities can offer more nuanced insights into understanding and addressing implicit bias more fulsomely in academic medicine.

\section{References}

1. Spector ND, Asante PA, Marcelin JR, et al. Women in pediatrics: progress, barriers, and opportunities for equity, diversity, and inclusion. Pediatrics 2019;144: e20192149.

2. Canadian medical education statistics 2018. Ottawa: Association of Faculties of Medicine of Canada; 2018:237.

3. Bates C, Gordon L, Travis E, et al. Striving for gender equity in academic medicine careers: a call to action. Acad Med 2016;91:1050-2.

4. Mueller AS, Jenkins TM, Osborne M, et al. Gender differences in attending physicians' feedback to residents: a qualitative analysis. J Grad Med Educ 2017; 9:577-85.

5. Axelson RD, Solow CM, Ferguson KJ, et al. Assessing implicit gender bias in medical student performance evaluations. Eval Health Prof 2010;33:365-85.

6. Salles A, Awad M, Goldin L, et al. Estimating implicit and explicit gender bias among health care professionals and surgeons. JAMA Netw Open 2019;2: e196545.

7. Witteman HO, Hendricks M, Straus S, et al. Are gender gaps due to evaluations of the applicant or the science? A natural experiment at a national funding agency. Lancet 2019;393:531-40.

8. Wenneras C, Wold A. Nepotism and sexism in peer-review. Nature 1997; 387:341-3.

9. Kaatz A, Lee YG, Potvien A, et al. Analysis of National Institutes of Health R01 application critiques, impact, and criteria scores: does the sex of the principal investigator make a difference? Acad Med 2016;91:1080-8.

10. LaDonna KA, Ginsburg S, Watling C. "Rising to the level of your incompetence": what physicians' self-assessment of their performance reveals about the imposter syndrome in medicine. Acad Med 2018;93:763-8.

11. Girod S, Fassiotto M, Grewal D, et al. Reducing implicit gender leadership bias in academic medicine with an educational intervention. Acad Med 2016;91: 1143-50.

12. Devine PG, Forscher PS, Cox WT, et al. A gender bias habit-breaking intervention led to increased hiring of female faculty in STEMM departments. J Exp Soc Psychol 2017;73:211-5.

13. Sukhera J, Gonzalez C, Watling CJ. Implicit bias in health professions: from recognition to transformation. Acad Med 2020;95:717-23.

14. Carnes M. The American College of Physicians is working hard to achieve gender equity, and everyone will benefit. Ann Intern Med 2018;168:741-3.

Competing interests: Simone Vigod reports receiving royalties for authorship of materials related to depression and pregnancy, from UpToDate, Inc. No other competing interests were declared.

This article has been peer reviewed.

Affiliations: Department of Psychiatry (Hui, Vigod, Zaheer), University of Toronto; Department of Psychiatry (Sukhera), Schulich School of Medicine \& Dentistry, Western University; Women's College Hospital and Women's College Research Institute (Vigod), Toronto, Ont.; Department of Psychiatry (Taylor), University of Calgary, Calgary, Alta.; Institute for Mental Health Policy Research (Zaheer), Centre for Addiction and Mental Health, Toronto, Ont.

Contributors: Katrina Hui and Juveria Zaheer contributed to the conception and design of the work and drafted the manuscript. All of the authors revised it critically for important intellectual content, gave final approval of the version to be published and agreed to be accountable for all aspects of the work.

Correspondence to: Juveria Zaheer, juveria.zaheer@camh.ca 